This item was submitted to Loughborough's Research Repository by the author.

Items in Figshare are protected by copyright, with all rights reserved, unless otherwise indicated.

\title{
Physical education, school sport and looked-after-children: Health, wellbeing and educational engagement
}

PLEASE CITE THE PUBLISHED VERSION

https://doi.org/10.1080/13573322.2019.1628731

\section{PUBLISHER}

(C) Taylor \& Francis (Routledge)

\section{VERSION}

AM (Accepted Manuscript)

\section{PUBLISHER STATEMENT}

This is an Accepted Manuscript of an article published by Taylor \& Francis in Sport, Education and Society on $20 \mathrm{Jul}$ 2019, available online: http://www.tandfonline.com/10.1080/13573322.2019.1628731.

\section{LICENCE}

CC BY-NC-ND 4.0

\section{REPOSITORY RECORD}

O'Donnell, Chloe, Rachel Sandford, and Andrew Parker. 2019. "Physical Education, School Sport and Lookedafter-children: Health, Wellbeing and Educational Engagement”. Loughborough University. https://hdl.handle.net/2134/37929. 
Physical Education, School Sport and Looked-After-Children:

Health, wellbeing and educational engagement 


\begin{abstract}
In recent years, there has been unprecedented awareness within policy and research of the disadvantageous trajectories that looked-after children and young people (LACYP) often face; particularly in relation to their education, health and wellbeing (Sebba et al., 2015; Mannay et al., 2017). Despite the perceived capacity of sport, physical activity and physical education to contribute to young people's positive development (e.g. Bailey et al., 2009; Holt, 2016), relatively few studies have considered the place of such activities in the lives of LACYP or the impact that being looked-after can have on individuals' engagements with them. Presenting findings from a small-scale, qualitative study of LACYP in England, this paper explores the ways in which physical education and school sport (PESS) might be contextualised against broader life circumstances and experiences of care. Placing the personalised accounts of a group of LACYP alongside those of physical education (PE) teachers and local authority professionals, the paper examines varied perspectives and experiences of PESS and its relevance to LACYP. In particular, it highlights the extent to which the vulnerabilities of LACYP status may impact young peoples' perceptions of health, wellbeing and educational engagement in this field. The paper concludes by suggesting that whilst PESS may be seen to present a number of social, emotional and health benefits for LACYP, when located against a backdrop of broader life-course vulnerability, such benefits may be de-prioritised by those concerned.
\end{abstract}

Keywords: Physical education, School Sport, health and wellbeing, looked-after-children and young people (LACYP), qualitative research. 


\section{Introduction}

In recent years, looked-after-children and young people (LACYP) ${ }^{1}$ have received significant attention within UK government policy and legislation (Hayden, 2007) which has often been stimulated by public accounts of child neglect and abuse (Shaw and Frost, 2013). At the same time, a growing academic literature has facilitated a broader understanding of the lived experiences of LACYP, their marginalised status within the youth population and the lack of awareness amongst both professionals and peers of the issues that they face (e.g. Selwyn, 2015a). A common theme within this literature is the plight of LACYP regarding the stability of family, peer and school relationships. In turn, the health and wellbeing of LACYP has attracted increasing attention, as has that of educational trajectories; both perhaps attributable to the well-documented evidence that LACYP are susceptible to poorer health and are more likely to have special educational needs (Cameron et al., 2015; Mannay et al., 2015).

It is widely acknowledged that children and young people within the UK care system have poorer levels of mental and physical health than their peers (e.g. Selwyn et al., 2017). Research shows that this is likely to be associated with the reasons behind children and young people being taken into care (such as abuse and/or neglect), with at least two thirds having one physical health concern and almost half suffering from mental health difficulties (Centre for Social Justice, 2014; Selwyn, 2015b). Evidence suggests that such issues may hinder cognitive and emotional development which, in turn, may have implications for educational outcomes (Jackson et al., 2011). Whilst statistics highlight the educational underachievement of this group, schooling has been recognised as playing an important role in the stability of those who

\footnotetext{
${ }^{1}$ In the UK, 'looked-after children' is the legal term for children and young people looked after by a local authority in accordance with the Children Act 1989. Under this Act, a local authority may remove a child or young person from their natural family setting by reason of a Care Order, Emergency Protection Order, under police protection or may provide them with accommodation (for more than 24 hours) with the agreement of the parents.
} 
are looked-after (Daniel and Wassell, 2002). What is also apparent is that the education, health and wellbeing profiles of LACYP are significantly shaped by their home, school and community backgrounds which, again, frequently demonstrate key markers of social deprivation, abuse and/or neglect (Stein, 2012). Such findings have played an important role in raising the profile of this previously under-researched group and have contributed to a range of developments in relation to policy and practice (Hayden, 2007).

This paper presents findings from a small-scale qualitative study that sought to explore the physical education and school sport (PESS) experiences of LACYP in England. Drawing upon data gathered from LACYP, as well as PE teachers and local authority professionals, the paper examines LACYP's attitudes towards and experiences of PESS from multiple perspectives. Moreover, in looking at PESS within the wider context of LACYP's experiences, it looks to highlight the extent to which the vulnerabilities of LACYP status may shape young peoples' perceptions of health and wellbeing more broadly, thereby impacting their desire to undertake or prioritise sport/physical activity (PA) in the school context. In so doing, it seeks to shed light on this under-researched area and offer implications for professional practice and future research.

\section{Sport, PE and physical activity for marginalised groups}

There is a significant amount of literature which suggests that sport/PA can be a provider of developmental qualities, not just for LACYP but for wider society (e.g. Armour et al., 2013; Holt, 2016). Of course, sport has long since been viewed by policy-makers, practitioners, and academics alike as an agent for stimulating personal and social change, particularly within the lives of young people (Nichols, 2007). In turn, research has pointed to the offering of sport for marginalised populations as a useful mechanism within the provision of social welfare services 
(Green, 2008). Others have cited sport as a diversionary tool or deterrent to anti-social behaviour with the view that participation provides a legitimised alternative to violence or a lawful form of excitement (see Parker, et al., 2017; Morgan and Parker, 2017). Indeed, for young people within the criminal justice system, the provision of sport has been recognised as imperative for the positive effects in increasing children and young people's self-esteem, reducing anxiety, and improving health (Ministry of Justice, 2016).

Furthermore, it has been suggested that participation in sport can facilitate young people's social and moral development through 'character building' and the acquisition of life skills (Sandford et al., 2006). Schroeder (2005) has argued that sport can mimic many of the challenges of everyday life, thereby enabling young people to learn the skills they need to deal effectively with such challenges. This is particularly important for young people with fewer choices and opportunities who may require extra support to develop their identity, social skills and levels of resilience. That said, the empirical and theoretical basis for the potential of sport to act as a panacea for deep-rooted social problems remains contested (Bloyce and Smith, 2010; Coalter, 2013; Dacombe, 2013; Parker et al, 2014) and it has been argued that some caution needs to be exercised in this respect. In particular, Fraser-Thomas et al., (2005) note that many programmes targeting positive youth development through sport may in fact result in negative impacts, particularly with regard to physical and emotional development.

Nonetheless, the developmental potential of sport/PA within educational settings has also received significant attention in recent years with the provision of PE (as a compulsory National Curriculum subject) and School Sport (as voluntary extra-curricular activity) being high on the UK government's agenda. Policy narratives here present sport not only as a mechanism for encouraging healthy and active lifestyles but also as "a tool for social good" in 
its capability to display "character building, discipline, morality, ethical behaviour and the reduction in social exclusion" (Girginov, 2008, p.50). Such arguments are put forward on the basis that PESS provides experiences that do not occur elsewhere in the curriculum and has the potential to make a valuable contribution to children, school and the wider community (Bailey et al., 2009). Given the purported capability of sport/PA to promote pro-social skills and behaviours, PESS is considered (by some) to be a valuable mechanism via which to re-engage disaffected pupils (Sandford and Duncombe, 2011). Further evidence implies that PA can provide children and young people with substantive health benefits and improved psychological and behavioural outcomes, as well as promoting notions of resilience, inclusion, and team-building (Janssen and LeBlanc, 2010). In addition, it has been noted that a positive relationship exists between PA levels and academic attainment (Public Health England, 2014).

\section{Sport, PE and physical activity in the lives of LACYP}

As one of the most disadvantaged groups in society, LACYP are at risk of a range of adverse social, educational and health outcomes (Sebba et al., 2015). In turn, concerns regarding the systematic underachievement of this group have been linked to the promotion of activities that support physical, social and psychological development. Despite the UK government promoting sport as an opportunity to alleviate previous levels of disadvantage (Department for Children Schools and Families, (DCSF) (2009), some young people, such as LACYP, face a series of wider obstacles that necessarily hinder their participation, e.g. a lack of motivation, difficulties in accessibility, and/or shortfalls in the recognition of specific needs (Schroeder, 2005; Quarmby et al., 2018). LACYP have been identified as "one of the groups most in need of regular engagement in physical activity for health", yet they remain amongst the least likely to access PESS provision (Armour et al., 2011, p. 221). 
Quarmby (2016) notes that their disadvantaged backgrounds make it more likely that LACYP have already been excluded from some physical activities prior to entering care and that time away from mainstream education means that they often miss out on school-based sporting activities, including PE and extra-curricular clubs. Yet alongside the work of children's and youth services, schools can play an important role in supporting these young people to develop their aspirations and interests (Prison Reform Trust (PRT), 2016). Facilitating LACYP's participation and offering them the chance to enjoy the benefits of sport/PA (and, within the school context, PESS), may enhance not only their physical, but their psychological wellbeing (Murray, 2013). As Hollingworth (2012) has argued, sport/PA can be integral to the development of social capital, resilience and identity for LACYP, as well as contributing to emotional, mental and physical health.

In the context of residential homes in the UK, Quarmby (2014) has identified difficulties for young people in accessing sport/PA due to domestic constraints and disrupted patterns of participation emanating from placement (home-life/domestic) changes. In addition, Sport England (2012) have highlighted that the more life-course 'transitions' children and young people face (i.e., moving schools, moving area, time out of education etc.), the less likely they are to participate in sport (see also Hollingworth, 2012). Cameron and colleagues (2015) concur that when planning for changes in schooling, a child's involvement in clubs and sports activities should be maintained. Regular engagement in PA, for example, has been found to provide a sense of structure to LACYP's lives that they may not experience elsewhere (Farineau and McWey, 2011; Hollingworth, 2012). However, research in the US with foster carers found that over half of those surveyed were unaware of the activities LACYP were involved in prior to placement in their homes (Fong et al., 2006). In the UK, an individual's Personal Education Plan (PEP) is intended to circumvent this issue by providing information about a young 
person's education and wider extra-curricular activities (DCSF, 2009).

Despite sport/PA routinely being used as a vehicle to engage marginalised young people (Sandford et al., 2006), to date few studies have considered the role of PESS in the lives of LACYP. Instead the focus has been placed upon more generalised accounts of leisure-time provision (Safvenbom and Sarndahl, 2000), extra-curricular activities (Farineau and McWey, 2011) or sport/PA pursuits (see Quarmby, 2014), with the majority of scholars utilising quantitative measures and rarely including LACYP as participants (see also Quarmby and Pickering, 2016). This has led Quarmby (2014) to assert that LACYP represent a 'hidden group' in relation to sport/PA policy and practice and that more research is needed in this area. It has also been argued that teachers need sufficient knowledge about LACYP, particularly around social and psychological factors that shape their engagement, to ensure that they do not miss important opportunities for them to access (and reap the potential benefits of) PESS (Armour et al., 2011; Quarmby et al., 2018). This paper seeks to add to these debates by foregrounding the voices and perspectives of LACYP, as well as those who work with and for them.

\section{Method}

The empirical findings featured here comprise part of a wider research project which sought to investigate the PESS experiences of a small cohort of LACYP $(n=10)$. The research was driven by a constructionist ontology and interpretive epistemology with the aim of eliciting the subjective interpretations of the everyday lives of respondents in relation to their experiences of sporting provision both inside and outside of educational settings, with a specific focus on PESS (Bryman, 2016). Data collection took place between January 2015 - March 2016 over three phases and was undertaken by the lead author. 


\section{Phase 1}

The first phase comprised a survey and follow-up, one-to-one telephone interviews with local authority professionals holding responsibility for the education of LACYP (including Virtual School Headteachers (VSH) and Educational Development Officers (EDO) ${ }^{2}$ ) to ascertain what they understood about the PESS experiences of LACYP. In the first instance, the survey was sent electronically to all VSHs in England ( $\mathrm{n}=153$ ) (with an accompanying message to forward, as required, to relevant colleagues) receiving a total of 46 responses $(30 \%){ }^{3}$. The data generated through the survey consisted of open and closed responses to questions that covered issues such as: the policies/processes that shape provision for LACYP with regard to PESS; the perceived influence of care experiences on LACYP's experiences of PESS; the potential benefits of PESS for LACYP; and the challenges faced by LACYP in PESS. Responses were manually collated and coded in order to facilitate the identification of key issues and concepts which were used to generate subsequent questions for follow-up interviews with this cohort. All survey respondents who indicated that they were willing to be contacted for interview were invited to do so and a total of 10 telephone interviews were carried out, each lasting between 30-60 minutes. This interview cohort comprised six females and four males, with job titles including VSH ( $\mathrm{n}=6$ ), Assistant VSH ( $\mathrm{n}=1$ ), Education Development Officer ( $\mathrm{n}=2$ ) and Teacher Advisor $(n=1)$

\section{Phase 2}

The second phase of data collection focused on the voices of LACYP. It is noted that there has been a rather adult-centric focus to previous research with LACYP, with accompanying calls

\footnotetext{
${ }^{2}$ In the UK, Virtual School Headteachers (VSH) have a statutory role in the education of LACYP and are responsible for monitoring and promoting the education of all children in care within their authority (DfE, 2014). Educational Development Officers are often employed by local authority children's services to help develop, implement and monitor key education plans, based on local priorities and the national agenda.

${ }^{3}$ Fifty-seven of these emails failed to reach the designated respondents due to redundant contact information. In turn, six questionnaires were not fully completed and thus were not included in the analysis.
} 
for studies to adopt more participatory youth voice perspectives (Quarmby and Pickering, 2016). Including space within this study for both professional/practitioner and LACYP voices was therefore deemed valuable in order to help address this perceived deficiency and offer opportunities for different perspectives to be gleaned. This phase of the research consisted of two group interviews and 11 individual interviews with a total of 10 LACYP. This cohort comprised four males and two females, aged 12 to 19 years of age; seven of whom were currently in care (either in foster care or residential homes) and three who were care leavers. In terms of educational status, five participants were still at school, three attended college (postcompulsory education), one was undertaking an apprenticeship programme, and one had left education and was now working. Interviews were based on a number of broad questions around issues relating to PESS and extra-curricular activities (e.g. how does taking part in PESS make you feel? What affects your enjoyment of PESS? Who supports your participation in PESS?). Further probing was used to identify individual experiences e.g., in relation to the perceived benefits, barriers and challenges to participating in PESS. Participatory activities, such as the creation of timelines/life maps, were used within some of the interviews in order to engage respondents and stimulate conversation (Alderson and Morrow, 2011).

There are notable difficulties in conducting research with LACYP including issues of access, consent and safeguarding (Quarmby, 2014; Quarmby et al., 2018). This study faced challenges in relation to securing access and required flexibility and a willingness to adapt. For example, to facilitate a sense of security, interviews took place in a variety of locations including participants' schools and homes, coffee shops, restaurants and at organised events/activities. Interviews lasted between 45-90 minutes and were (with the LACYP's consent) recorded and transcribed verbatim. Field notes were also taken in order to provide contextual detail. 


\section{Phase 3}

Phase 3 comprised both a survey and individual telephone interviews with PE teachers who taught at schools located within the three local authorities responsible for LACYP participants. ${ }^{4}$ An electronic survey was sent to all secondary, special schools and Pupil Referral Units (PRUs) within these three localities, totalling 139 institutions. The survey included open and closed questions concerning respondent awareness of LACYP (and the issues that they can face) and their preparation for/experiences of delivering PESS for LACYP (e.g. What training have you received around working with LACYP?; What can LACYP gain from participating in PESS?; What challenges do LACYP face with regard to PESS?) Sixteen responses were received with four respondents agreeing to take part in a follow-up interview. Despite contacting all four participants, only two (both male Heads of PE) were available for interview. These interviews each lasted approximately 45 minutes.

\section{Data Analysis}

Thematic and axial coding was used in relation to the analysis of interview data, where a cyclical process of examination and inductive interpretation was adopted to draw out key meanings in response to the primary aims of the research and in line with the themes and concepts identified from the existing literature (Charmaz, 2014). It is worth noting that the questions asked of each participant group, while allowing for some specific focus on issues relevant to the particular cohort (e.g. policies/structures for VSHs, personal experiences for LACYP and school-based practice for PE teachers), also covered areas of common ground (e.g. perceived benefits of/challenges to PESS participation for LACYP). Asking similar questions in each context, along with using different methods to generate data, was intended to provide

\footnotetext{
${ }^{4}$ Data collection with LACYP was originally secured through three separate local authorities, one of which withdrew at a later stage.
} 
some capacity for triangulation and a means of testing the trustworthiness of the data (Anney, 2014). Data were analysed in four stages. Firstly, transcripts were read in full to gain an overview of the findings. Secondly, each transcript was individually coded and indexed, whereby a capturing of the different aspects of participant experience took place. Thirdly, these experiences were categorised into over-arching topics which were chosen on account of the fact that they broadly encompassed the key issues emerging from the data. The final stage of analysis involved the organisation of these topics into generic themes by further exploring key issues around respondent experience and framing those within the context of existing debate (differentiated by respondent group). These themes provide the framework around which our findings are presented and comprise discussion in two key areas: (i) LACYP perceptions of health, wellbeing and PESS, and (ii) LACYP behaviour, attitude and mind-set towards PESS.

\section{Health, wellbeing and PESS}

Historically speaking, physical wellbeing within the context of child protection and safeguarding has been a key priority for those responsible for LACYP. In turn, statistics demonstrate that looked-after children are four times more likely to suffer from mental health problems than their peers, with 56\% of LACYP in England having a special educational need, compared to $14 \%$ of others their age (see DfE, 2018b). Despite arguments to suggest that sport/PA should not be seen as a panacea for complex social problems, survey responses in this study from local authority professionals suggested that PESS may indeed be viewed in this way by some. For example, more than $90 \%$ of respondents to the Phase 1 survey stated that PESS was beneficial for LACYP, with many referring to its capacity to facilitate physical, social and emotional wellbeing e.g. through encouraging a healthy lifestyle, developing social skills, building confidence and improving self-esteem. Interviews with local authority professionals 
confirmed these views, as exemplified below by John, a VSH: ${ }^{5}$

Our view has always been that a happy child is a progressive child, and in terms of participating in other activities ... we also feel that we have seen a direct relation between increased levels of motivation, confidence, self-esteem leading to greater participation in school-based activities ... whether it's schools or other activities. For example, from youth services as well, where they've been involved in extra-curricular activities, we have seen a marked improvement in the level of contribution (and) participation.

Recent statutory guidance on promoting the health and wellbeing of LACYP does not identify PE (or indeed PA) as a specific promoter of wellbeing and physical health (see DfE, 2015; DoH, 2015). The importance of LACYP accessing PESS on account of the perceived benefits is reiterated below by Liam, an EDO:

I think it's very important because the social interaction is one [thing], but also it's about ... personal development for children. Because it's good and well the government rhetoric highlighting that they're [LACYP] not up to speed with their peers or ... on par with their peers [in terms of academic attainment], but ... I think sometimes people do ... need to minimize the impact of trauma, bereavement, loss. And how they [children] get around this, it's not always engagement in education, it's about getting the holistic bond of activities, but to teach those skills and also areas of weakness.

For Liam, supporting LACYP in their personal development was not simply about pursuing

\footnotetext{
${ }^{5}$ In the interests of anonymity, pseudonyms have been used throughout.
} 
academic engagement, rather participation in a broad range of activities (including PESS) was central to addressing the social and emotional difficulties associated with being looked-after (see APPG, 2012). The National Institute for Health Care Excellence (NICE) and the Social Care Institute for Excellence (SCIE) (2010) recommend that social workers and independent reviewing officers ensure access to creative arts, physical activities, and other hobbies and interests to support and encourage the overall wellbeing and self-esteem of LACYP. Such suggestions relate to previous research that has recognised that participation in extra-curricular activities supports a general sense of psychological wellbeing (Darling, 2005) and that there are connections between on-going involvement in such activities and the development of prosocial behaviours (Zaff et al., 2003).

Perhaps unsurprisingly, due to their role in subject delivery, evidence of perceived benefits arising from PESS participation was commonplace during data collection with PE teachers, with all 16 survey respondents attesting to the potential advantages for LACYP in this respect. Examples included: benefits to health; social and emotional wellbeing; confidence; selfesteem, communication skills, and a sense of belonging. However, the consensus was that these benefits were, to some extent, the same for 'all children'; something also articulated by David (a Head of PE) in his interview:

Confidence, self-efficacy ... leadership qualities. The ability to challenge themselves; massive amount of challenge, the need to achieve is there. It can remove the fear of failure ... a stress release. It's endless. And again, I know we're talking specifically about lookedafter children, but it's not specific to them, it's to all children ... I can think of lookedafter children that excel in extra-curricular and physical activity, in motivation, in 
confidence, much better in PE than other students. But then ... some don't even come to PE, so it really depends on the individual.

The notion that the associated benefits of participating in PESS are not limited to LACYP is important, since it implies that whilst PESS may improve social and emotional aspects of LACYP's wellbeing, such improvements are not necessarily perceived to be any more beneficial than for other young people. David went on to argue that although PESS is important for those disengaged from education, sport/PA outside of the school environment can be just as beneficial for improving LACYP wellbeing and PESS should therefore be seen as just one part of the bigger picture:

[PE is] as important as any Maths or English exam, a priority ... [because] it's the only subject in school that keeps kids living longer ... It's the only subject in school that provides lifelong learners that encourages healthy, happy lifestyles ... The more [extracurricular] activities these students can do, the greater their wellbeing. I'm not saying that it has to be in school, but school's one of the easiest areas for them to access ... They say, "Oh I hate my school, I hate my teachers, I hate everything about it", that's fair enough, as long as they're going down to their local football club, if they're happy there that's not a problem.

David went on to highlight that alongside disengagement from PE, LACYP may fail to engage with schooling more generally and that this had the potential to impact their engagement with PESS. David also raised further issues concerning participation in sport/PA away from school, deeming them harder to access but just as important for wellbeing. He argued that LACYP may gain a greater measure of improved wellbeing in sport/PA outside of the school context, since 
they may not directly associate this with negative experiences of schooling. Similar findings were demonstrated by Hollingworth (2012) who noted that sport/PA can be integral to enhancing emotional, mental and physical health for LACYP. Interestingly, Bailey et al., (2009) argue that participating in extra-curricular PA both within and beyond the educational context can positively affect cognitive, affective and social developments. In this respect, it is possible again to see PESS as just one vehicle through which LACYP can gain potential benefits from sport/PA participation, along with opportunities beyond the school context. Certainly, being given opportunities to participate in community activities has previously been recognised by LACYP themselves as an important way of developing social skills, confidence and self-esteem (Selwyn, 2015a).

To summarise thus far, educational professionals within this study perceived PESS to be a platform via which LACYP might positively develop self-esteem, confidence and other wellbeing traits. Data highlighted, however, that this was unlikely without engagement with PESS in the first instance. Significantly, this finding was inconsistent with almost all of the LACYP participants, many of whom failed to indicate any perceptible improvements to wellbeing resulting from PESS. This could be due to a general lack of participation among this particular cohort, but may also reflect the negligible value that they attributed to the role of PESS within their lives. A significant finding in this respect was the behaviour, attitude and mind-set of LACYP towards PESS, a topic to which we now turn.

\section{Behaviour, attitude and mind-set towards PESS}

As we have seen, the extent of behavioural problems among LACYP has been welldocumented. From the data collected in this study, a clear finding was that LACYP's behaviours and attitudes towards schooling were closely aligned with how much they valued 
and engaged in PESS. This is perhaps unsurprising, given that LACYP can often suffer from emotional, social and behavioural (ESB) difficulties and special educational needs (SEN) and that this can create significant barriers for learning in general (DfE, 2018b). Such issues are demonstrated in the extract below, taken from an interview with Robert (a VSH), who was asked about potential barriers to LACYP's engagement with PE:

It's tough to generalize because it's on an individual basis. But what you would say is, as a generalization, there are some [LACYP] whose behaviour can be volatile because of the emotional need that they have in attachments ... the main problem isn't just specific to PE, it's specific to school.

Robert argues that the behaviour of LACYP is a result of the emotional difficulties associated with their wider circumstances. This is also recognised in recent UK policy documentation (see DfE, 2018a) which notes that the impact of trauma, abuse or additional vulnerabilities for LACYP can reflect in behaviour that is considered challenging. Robert also puts forward the idea that these behavioural difficulties may not only impact PE, but the individual's entire experiences of schooling. Evidence of this was forthcoming from LACYP themselves. Here, for example, Shannon explains the circumstances behind her own educational disengagement:

My attendance was lower than 28\%. I used to just ditch school behind the sports hall. They knew exactly where I was and didn't care. The fact is I was unkempt, because I had the parents that I had. They didn't give a toss really to be honest ... Because obviously my home life wasn't that good. I had so much going on. I had my brother and sister taken away when I was at [PRU], then I was taken into care. I was moved from my first care 
home to Judy [current foster carer]. My first carer was terrible. I was there six months and they just cared about the money ... (Care Leaver, aged 17, apprenticeship)

Within the LACYP literature such circumstances are common place (e.g. Ministry of Justice, 2016). Shannon's behaviour appeared to stem from her unstable home-life and was exacerbated by her experiences of bullying at school and her perception of not being listened to by a senior member of staff, who she subsequently attacked with a chair; hence her referral to alternative educational provision (a PRU). Problem behaviour in school is commonly cited as one of the associated risk factors for criminal involvement and poor prospects when older (e.g. Hayden, 2007). This was certainly the case for Shannon, who also disclosed during interview that she had been involved with the police at the age of 13. The Prison Reform Trust (2016) estimate that up to half of all children and young people involved in the criminal justice system are, or have been, in care. The disproportionate criminalisation of LACYP is suggested to be consistent with accounts that predict a relationship between socio-economic status and contact with the youth justice system (Bateman, 2017). Others suggest that the majority of LACYP start to offend prior to becoming looked-after (Darker et al., 2008). Irrespective, LACYP remain overrepresented in the criminal justice system (DfE, 2018a).

Amidst the data collected from PE teachers, similar issues regarding LACYP's behaviour were conveyed by survey respondents as factors affecting engagement with PESS. For example, the Head of a PE at one secondary school stated that "often these [LACYP] students come with underlying issues that affect their behaviour ... this shouldn't provide these students with an excuse to behave this way, but staff can have a little sympathy." Data highlight that while some PE teachers may be aware of the difficulties that LACYP might face, many do not feel they know enough about how to help address these. There would certainly appear to be a lack of 
training and information provided on how to offer support with such difficulties, with $88 \%$ of teacher survey respondents commenting that they had not received any training in this area since they started teaching. Discussions from practitioners regarding LACYP's behavior were consistent with data from some youth respondents, who spoke about how challenges in their broader life circumstances might 'play out' negatively within the school context - as Nathan's account of his time at secondary school revealed:

I turned really like defiant and stuff 'cos of like all the stuff that was happening. I couldn't really be bothered to follow any orders ... I'd get the bus in and go out for a fag, stuff like that ... If I had no trouble at home or anything, I would go in fine and I'd probably be fine for the day. But if I had like an argument the night before or in the morning or something then I'd definitely be off at school and then like if anyone, like .... said anything, then I would just go mad. (Currently in care, aged 16 years, college student)

Similarly, 19-year-old Jamie explained that he would often get angry at school and display negative behaviours:

It was all my built-up anger towards my Mum, I think. It was mainly 'cos so many times I wanted to just punch something or throw something in the house or just destroy the house completely, but I never did 'cos I never had the courage. But in school I took from [an] example from everyone else kicking off that I could do it. That it was acceptable in my head. (Care Leaver, college student)

Both Nathan and Jamie imply that their behaviours were directly affected by what they experienced outside of school. APPG (2012) note that there are a disproportionately large number of LACYP with deep-rooted and complex learning and behavioural needs who require 
specific educational support and interventions. This view was certainly shared by local authority respondents in this study and exemplified by Debbie, a VSH:

I think it's just the schools that go the extra mile who have flexible support, who have identified a key adult that keeps an eye out for that child to go to when they need it, who use a behaviour management system that has flexibility ... Just to understand what's behind the behaviour and why it's occurring and show a bit more understanding, empathy. Understanding that these kids' lives are really tough and if you were an adult going through half of the stuff they are going through you would be struggling.

Such sentiments were also apparent in the findings from the PE teacher survey. For example, in response to being asked how they might address the kinds of barriers and issues that LACYP may face in relation to PESS, one Head of PE stated that teachers could be "more accepting/understanding of their [LACYP] behaviour/emotional issues and why there may be non-participation in clubs." Indeed, within the study there was evidence to suggest that where teachers were perceived to know and understand something of a LACYP's background, there was a more positive relationship between student and teacher. As Kalaya commented:

I had a really good relationship with Miss Peterson, like she was nice, she understood me. You know how some teachers would just shout at you and kinda like hate you after a while cos you didn't turn up and stuff. But Miss Peterson she was like "why aren't you turning up, I can make it [lessons] better". [Researcher: So why do you think Miss Peterson understood you more?] She was nicer. And she like knew about from when I was at home and like the other teachers, they didn't really know. (Currently in care, aged 17 years, college student) 
It is worth noting that, despite the negative examples above, some LACYP have positive experiences in the care system (achieving good emotional and physical health), do well in their education, and have successful careers (NICE/SCIE, 2010). This was also reflected in the data from this study which revealed that the few LACYP who actively engaged in PESS had a positive mind-set towards their wider educational experiences. For example, Year 8 pupil Lucy (aged 13) explained the influence of her friends on her engagement with school and extracurricular activities asserting that "I know that I can't get distracted because if I want the best grades in Year 11 then I have to work hard". The importance of achieving in education was also expressed by Bradley, aged 15 and currently in year 11 (the final year of compulsory schooling). He explained that "When I'm older I want to be a forensic science investigator or physicist". However, the importance of education for Bradley was not limited to aspiring to achieve, since he also revealed that it was largely associated with the feeling of belonging that being at school provided:

'Cos like it's like another family isn't it. You go to school, like everyone's the same, you're all unique in your own way, but you're all part of one big family and feel wanted. And it's where I can shine, because at home no one really cares what I do, and when I start telling them about science they're like "Oh Bradley shut up". But in school they all listen and they're like “Oh thanks Bradley that's really useful”. (Currently in care, aged 15 years, school student)

The experiences that secondary school students Lucy and Bradley shared emphasise how education was a source of stability within their lives, a point which Hollingworth (2012) identified as important for both those in and leaving care. Whilst within this study such views were in the minority, importantly, those LACYP who did engage/had engaged in PESS (e.g. 
Lucy and Bradley) also articulated a positive attitude and mind-set towards schooling more broadly, whilst those who expressed a dislike for and/or disengagement from PESS (e.g. Jamie and Shannon) exhibited behavioural issues during their time at school. While there are undoubtedly complexities at play here and simple causality cannot be drawn, these data do serve to support previous findings which suggest that taking part in extra-curricular activities is associated with higher academic aspiration/attainment and positive attitudes to schooling (Darling, 2005).

\section{Conclusion}

In this paper we have attempted to explore the PESS experiences of a small group of UK-based LACYP. In so doing, we have sought to shed light on the complex lived experiences of an under-researched and 'hidden' group of young people within the context of physical education research (Quarmby, 2014). In drawing upon the voices of both LAYCP and the adult professionals who work with them, we have sought to uncover some of the social and emotional factors which might impact LACYP in relation to their attitudes towards, participation in and experiences of PESS.

Our findings suggest that LACYP's motivations towards/participation in PESS was largely shaped by their sense of wellbeing and that this had a significant influence on their wider life choices around sporting participation. Indeed, it was notable that while research questions were focused around PESS specifically, responses from all respondent groups often related to the broader context of LACYP's lives. There is a growing recognition that the spaces and places in which young people spend time are important in shaping their attitudes and dispositions towards participation in sport/PA and, moreover, their sense of self (Sandford and Quarmby, 2019). Data from this study would appear to support this, indicating how broader experiences 
might play a key role in influencing behaviours. All respondent groups identified the social and emotional challenges faced by LACYP and acknowledged that they had the potential to impact their educational engagement especially within PESS. However, data also point to some of the improvements in wellbeing that LACYP might potentially gain from participation in PESS.

While this developmental potential was a shared view among local authority professionals and PE teachers, it is notable that LACYP respondents did not always articulate their experiences of PESS in this way. Indeed, findings indicate that the overall behaviours and mind-set of LACYP could play a pivotal role within their experiences of PESS. Expressing undesirable behaviours as a form of communication was found to be a barrier for some LACYP with regard to engaging with PESS and schooling more generally. However, those LACYP who reported positive PESS experiences did not refer to such behaviours and appeared to have a more positive outlook towards their educational lives. These findings could be attributed to the fact that most young people who took part in the study professed a lack of interest in PESS, thus de-prioritizing its importance.

The challenge of engaging practitioners within this study has been acknowledged and is a notable limitation. Nonetheless, the voices of teachers involved highlight some valuable points for consideration. For example, PE teacher respondents noted that there is often a lack of shared knowledge in schools concerning LACYP behaviours and, at times, a lack of understanding regarding the challenges they may face within broader life contexts. Teacher respondents also pointed to a lack of specific training and on-going CPD in this area. As such, there is perhaps an argument to be made for specific training for PE teachers, targeted at understanding the trajectories, experiences and potential outcomes of LACYP in order to be able to better support and accommodate them within PESS. On a broader scale, the APPG (2012) have suggested 
that more work needs to be done to help teachers understand what underpins the disruptive behaviours that LACYP often exhibit. Data generated within this study would appear to suggest that tailored training for PE teachers might be needed to help enhance LACYP's experiences of PESS. In this respect, Armour's (2014) work on pedagogical cases might present a useful framework to draw upon. Indeed, the creation of composite narrative case studies (drawn from research such as that presented here) could powerfully enhance teaching practice within PE, by bridging the gap between research, theory and practice and offering specifically tailored content that could be shared across the school context. Given that this study has identified the intersecting levels of influence at play within LACYP's PESS experiences, the VSH and associated local authority staff may also benefit from such training.

\section{References}

Alderson, P. and Morrow, V. (2011). The Ethics of Research with Children and Young People: A Practical Handbook. London: SAGE Publications Ltd.

All-Party Parliamentary Group for Looked-After Children and Care Leavers (APPG). (2012). Education Matters in Care. A report by the independent cross-party inquiry into the educational attainment of looked after children in England. HMSO/UCU.

Anney, V.N. (2014). Ensuring the Quality of the Findings of Qualitative Research: Looking at Trustworthiness Criteria. Journal of Emerging Trends in Educational Research and Policy Studies, 5(2): 272-281

Armour, K., Sandford, R. and Duncombe, R. (2011). Right to be active: looked-after children in physical education and sport, in K. Armour (Ed.) Sport Pedagogy: An Introduction for Teaching and Coaching. London: Pearson Education Limited. 
Armour, K.M., Sandford, R.A., and Duncombe, R. (2013). Positive Youth Development and Physical Activity/Sport Interventions: Mechanisms leading to Sustained Impact, Physical Education \& Sport Pedagogy, 18(3): 256-281.

Bailey, R., Armour, K., Kirk, D., Jess, M., Pickup, I. and Sandford, R. (2009). The educational benefits claimed for physical education and school sport: an academic review, Research Papers in Education, 24(1): 1-27.

Bateman, T. (2017). The state of youth justice 2017: An overview of trends and developments. London: National Association for Youth Justice.

Bloyce, D. and Smith, A. (2010). Sport Policy and Development: An introduction. Abingdon: Routledge.

Bryman, A. (2016). Social Research Methods. Oxford: Oxford University Press.

Cameron, C., Connelly, G. and Jackson, S. (2015). Educating Children and Young People in Care: Learning Placements and Caring Schools. London: Jessica Kingley Publishers. Centre for Social Justice. (2014). Survival of the fittest? Improving the life chances for care leavers. London: The Centre for Social Justice.

Charmaz, K. (2014). Constructing Grounded Theory: A Practical Guide Through Qualitative Analysis. London: Sage Publication.

Coalter, F. (2013). Sport for development: What game are we playing? Abingdon: Routledge.

Dacombe, R. (2013). Sports clubs and civic inclusion: rethinking the poverty of association, Sport in Society, 16(10): $1263-1278$.

Daniel, B. and Wassell, S. (2002). The School Years: Assessing and Promoting Resilience in Vulnerable Children 2. London: Jessica Kingsley Publishers.

Darling, N. (2005). Participation in extracurricular activities and adolescent adjustment: cross- sectional and longitudinal findings, Journal of Youth and Adolescence, 34: 493-505. 
Darker, I., Ward, H., and Caulfield, L. (2008). An analysis of offending by young people looked after by local authorities, Youth Justice, 8(2):134-48.

DCSF. (2009). Improving the attainment of looked-after young people in secondary school: Guidance for schools. Nottingham: DCSF.

DfE. (2015). The Children Act 1989 guidance and regulations: Volume 3: planning transitions for care leavers. London: Department of Health.

DfE. (2018a). The national protocol on reducing unnecessary criminalisation of looked-after children and care leavers. London: Department of Health.

DfE. (2018b). Outcomes for children looked after by local authorities in England, 31 March 2017. London: Department of Health.

DoH. (2015). Future in mind: Promoting, protecting and improving our children and young people's mental health and wellbeing. London: Department of Health.

Farineau, H. and McWey, L. (2011). The relationship between extracurricular activities and delinquency of adolescents in foster care, Children and Youth Services Review, 33: 963-968.

Fong, R., Schwab, J., and Armour, M. (2006). Continuity of activities and child well-being for foster care youth, Child and Youth Services Review, 28: 1359-1374.

Fraser-Thomas, J.L., Côté, J. and Deakin, J. (2005). Youth sport programs: an avenue to foster positive youth development, Physical Education and Sport Pedagogy, 10(1):1940

Girginov, V. (2008). Management of Sports Development. Oxford: Butterworth-Heinemann.

Green, M. (2008). Sport as an agent for social and personal change, in V. Girginov (Ed.) Management of Sports Development. Oxford: Elsevier.

Hayden, C. (2007). Children in trouble: the role of families, schools and communities. Basingstoke: Palgrave Macmillan. 
Hollingworth, K. (2012). Participation in social, leisure and informal learning activities among care leavers in England: positive outcomes for educational participation, Child and Family Social Work, 17: 438-447.

Holt, N. L. (Ed., 2016). Positive youth development through sport (2nd ed.). London: Routledge.

Jackson, S., Cameron, C., Hollingworth, K. and Hauri, H. (2011). England, in S. Jackson and C. Cameron (Eds.) Final Report of the YiPPEE Project: Young People from a Public Care Background: Pathways to Further and Higher Education in Five European Counties. London: Thomas Coram Research Unit, Institute of Education, University of London.

Janssen, I. and LeBlanc, A. (2010). Review Systematic review of the health benefits of physical activity and fitness in school-aged children and youth, International Journal of Behavioral Nutrition and Physical Activity, 7(40): 1-16.

Mannay, D., Staples, L., Hallet, S., Roverts, L., Rees, A., Evans, R. and Andrews, D. (2015). Understanding the educational experiences and opinions, attainment, achievement and aspirations of looked-after children in Wales. Cardiff: Welsh Government.

Mannay, D., Evans, R., Staples, E., Hallett, S., Roberts, L., Rees, A. and Andrews, D. (2017). The consequences of being labelled 'looked-after': Exploring the educational experiences of looked-after children and young people in Wales, British Educational Research Journal, 43(4): 683-699.

Ministry of Justice (MoJ). (2016). The government response to Charlie Taylor's Review of the Youth Justice System. London: Ministry of Justice. 
Morgan, H. J. and Parker, A. (2017). Generating 'recognition', 'acceptance' and social inclusion in marginalised youth populations: The potential of sports-based interventions, Journal of Youth Studies, 20(8): 1028 -1043.

Murray, C. (2013). Sport in care: Using freedom of information requests to elicit data about looked after children's involvement in physical activity, British Journal of Social Work, 34: 1347-1363.

NICE/SCIE. (2010). Promoting the quality of life of looked-after children and young people. London: NICE.

Nichols, G. (2007). Sport and crime reduction. Oxon: Routledge.

Parker, A., Meek, R. and Lewis, G. (2014), 'Sport in a youth prison: Male young offenders' experiences of a sporting intervention', Journal of Youth Studies, 17 (3): 381-396.

Parker, A., Morgan, H., Farooq, S., Moreland, B., and Pitchford, A. (2017). Sporting intervention and social change: Football. Marginalised youth and citizenship development. Sport, Education and Society, 24(3): 298-310.

Prison Reform Trust. (2016). In Care, Out of Trouble: How the life chances of children in care can be transformed by protecting them from unnecessary involvement in the criminal justice system. London: Prison Reform Trust.

Quarmby, T. (2014). Sport and physical activity in the lives of looked-after children, Sport, Education and Society, 19(7): 944-958.

Quarmby, T. (2016). Who Cares? Physical activity, families and children in care, in S. Dagkas and L. Burrows (Eds.) Families, Young People, Physical Activity and Health. London: Routledge.

Quarmby, T. and Pickering, K. (2016). Physical activity and children in care: A scoping review of barriers, facilitators and policy for disadvantaged youth, Journal of Physical Activity and Health, 13(7): 780-787. 
Quarmby, T. Sandford, R. and Elliot, E. (2018). 'I actually used to like PE, but not now: Understanding care-experienced young peoples' (dis)engagement with physical education. Sport Education and Society, DOI: 10.1080/13573322.2018.1456418

Quarmby, T., Sandford, R. and Pickering K. (2018). Care-experienced youth and positive development: an exploratory study into the value and use of leisure-time activities, Leisure Studies, DOI:10.1080/02614367.2018.1535614

Sandford, R.A., Armour, K.M. and Warmington, P.C. (2006). Re-engaging disaffected youth through physical activity programmes, British Educational Research Journal, 32 (2): 251-271.

Sandford, R. and Quarmby, T. (2019). Space, place and identity: new pressures in the lives of young people. In, V.A. Goodyear and K.M. Armour (Eds) Young People, Social Media and Health (Chapter 11: 117-131). London: Routledge.

Schroeder, K. (2005). Fit for life: Using sports as an educational tool for the inclusion of young people with fewer opportunities. Brussels: SALTO-YOUTH.

Sebba, J., Berridge, D., Luke, N., Fletcher, J., Bell, K. \& Strand, S. et al. (2015) The educational progress of looked after children in England: Linking care and educational data. Oxford: Rees Centre for Research in Fostering and Education and University of Bristol. 
Selwyn, J. (2015a). Children and Young People's Views on Being in Care: A Literature Review. Bristol: The Hadley Centre for Adoption and Foster Care Studies (and Coram Voice).

Selwyn, J. (2015b). Measuring Well-Being: A Literature Review. Bristol: The Hadley Centre for Adoption and Foster Care Studies (and Coram Voice).

Selwyn, J., Wood, M. \& Newman, T. (2017). Looked after Children and Young People in England: Developing Measures of Subjective Well-Being, Child Indicators Research, 10: 363. https://doi.org/10.1007/s12187-016-9375-1

Shaw, J. and Frost, N. (2013). Young People and the Care Experience: Research, Policy and Practice. Hove: Routledge.

Sport England. (2012). Sporting Habit for Life: Full report. Retrieved March 2014 from: https://www.sportengland.org/research/encouraging-take-up/key-influences/age/

Stein, M. (2012). Young People Leaving Care: Supporting Pathways to Adulthood. London: Jessica Kingsley Publishers.

Zaff, J., Moore, K. Papillo, A. and Williams, S. (2003). Implications of extra-curricular activity participation during adolescence on positive activities, Journal of Adolescent Research, 18(6): 599-630. 